\title{
Cage activity in the Virginia opossum
}

\author{
DONNA M. CONE AND A. L. CONE \\ LYNCHBURG COLLEGE
}

Cage activity of four Virginia opossums was measured twice daily (morning and night) under six levels of ambient illuminat tion (dark, less than 1, 2.5, 5, 25, $50 \mathrm{ft}$-c). Analysis of variance indicated that the Ss were significantly more active under the three lower levels of illumination than under the three higher ones and were significantly more active at night than in the daytime. In addition the Illumination by Time of Day variable was significant. This interaction between environmental stimuli and phases of the circadian rhythm cycle is discussed in terms of Bindra's hypothesized inverted U-shaped curve relating physiological arousal and performance.

Behavioral scientists have treated spontaneous locomotor activity as a behavioral index of the physiological arousal level of mammalian species (Duffy, 1962). Among the independent variables shown to significantly affect activity are food and water deprivation (Campbell, 1960; Campbell \& Sheffield, 1953), hormones (Hall \& Lindsay, 1938), drugs (Cavau, 1960), and environmental stimuli (Rietveld \& Tordoir, 1965). One of the most frequently studied environmental stimulus variables has been intensity of ambient illumination. Isaac \& DeVito (1958) found that diurnal rhesus macaque monkeys displayed increased cage activity with higher intensities of illumination, and Isaac \& Reed (1961) found that nocturnal Siamese cats displayed decreased cage activity with higher intensities of illumination. Thus, intensity of illumination seems to produce diametrically opposed effects on the amount of cage activity depending on the nocturnality or diurnality of the species. Aschoff's rule (Marler \& Hamilton, 1966) states that the period length of circadian activity in diurnal. animals decreases under higher intensities of constant ambient illumination while that of nocturnal animals increases under these conditions. The effects of intensity of illumination thus appear to be in opposite directions for measures of rhythm cycle length and for amount of activity in short test sessions. These two generalizations taken together led to the hypothesis that intensity of illumination interacts with phase of the circadian rhythm within a given species. To test this, the following factorial experiment was designed in which cage activity was measured twice daily under six intensity levels of ambient illumination. Wild opossum (Didelphis virginiana) were chosen as readily available nocturnal animals.

\section{Subjects}

The Ss were four male opossums, two each from two litters. These animals were born of feral mothers captured by hunters in the area. The Ss remained in an outdoor colony until 60 days after weaning. From two weeks before weaning and throughout the experiment they were handled daily. Sixty days after weaning and two weeks before the beginning of the experiment they were brought into the laboratory and housed in individual cages with nest boxes. These cages were adjacent to a southwest window. Purina dog chow and water were available at all times.

\section{Apparafus}

The activity cages consisted of upright plastic cylinders $15 \mathrm{in}$. in diameter and $18 \mathrm{in.} \mathrm{high.} \mathrm{These} \mathrm{cages} \mathrm{were}$ pivoted in the center and supported every $90^{\circ}$ by a sensitive microswitch which operated an electromagnetic counter through a pulse former. A 1/2 in. diameter pole extended vertically through the center of the cage to prevent the animal from registering high counts by sitting at the exact center of balance and making small movements such as those in breathing. The floor of the cage was raised 1 in. by a $1 \times 1$ in. mesh subfloor so that excrement could pass through.

Two feet above the top of the cage a light diffusing screen made of four layers of white tissue paper was placed. One foot above the tissue paper there was mounted a light socket into which bulbs of various wattages were inserted for the different levels of illumination. Levels of illumination were measured with a General Electric photographic light meter $1 \mathrm{ft}$ above the cage floor and consisted of dark, less than $1 \mathrm{ft}-\mathrm{c}$, $2-1 / 2 \mathrm{ft}-\mathrm{c}, 5 \mathrm{ft}-\mathrm{c}, 25 \mathrm{ft}-\mathrm{c}$, and $50 \mathrm{ft}-\mathrm{c}$. Illumination levels higher than $50 \mathrm{ft}-\mathrm{c}$ were not used because in preliminary tests they were found to raise the temperature within the test cage.

\section{Procedure}

Each animal was tested for $1 \mathrm{~h}$ and $15 \mathrm{~min}$ from midmorning until noon and from 10 PM until just after midnight each day for 24 consecutive days. Data from the first $15 \mathrm{~min}$ of each session were discarded to allow for any possible warmup or adaptation effect. Levels of illumination were randomly assigned to both day and night sessions for all four $\mathrm{Ss}$, with the exception that no level was repeated at a given time of day for a given $S$ before the complete replication of the experiment had occurred. Each replication, therefore, took six days, and the four replications of the 2 by 6 factorial design took 24 days.

\section{Results}

An analysis of variance was performed on data transformed $(\sqrt{x+1})$ according to the suggestion by Edwards (1960) for frequency data whose probable underlying distribution is Poisson. The analysis used was based on a model proposed by Walker \& Lev (1953) for factorial designs using Ss as their own controls.

The results of this analysis indicate that Illumination produced a highly significant effect on cage activity ( $F$ $=9.819, \mathrm{df}=5 / 30, \mathrm{p}<.01$ ) and that Time of Day pro- 


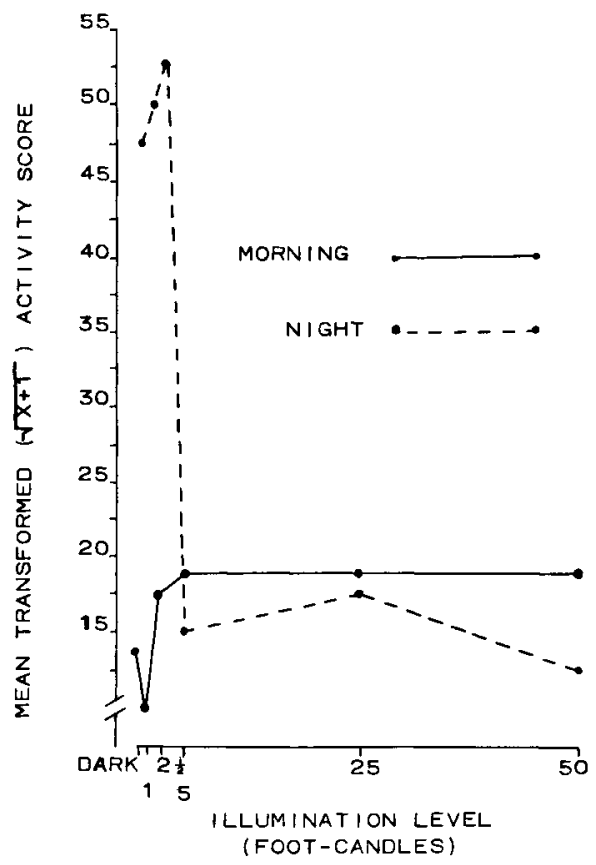

Fig. 1. Transformed activity scores as a function of level of illumination and time of day.

duced a significant effect on cage activity ( $F=16.028$, df $=1 / 3, p<.05$ ). In addition, these two variables were found to interact significantly $(F=24.359, \mathrm{df}=5 / 15, \mathrm{p}<$ $.0001)$. Examination of Fig. 1 shows that the gradients for morning and night cross between 2-1/2 and $5 \mathrm{ft}-\mathrm{c}$ and that both main effects are essentially attributable to the differences in the first three levels (Dark, $<1$, and $2-1 / 2 \mathrm{ft}-\mathrm{c})$. It should be noted that the Subjects variable used to remove effects of individual differences produced an $\mathrm{F}$ ratio which, while exceeding the .25 level, did not approach the .10 level of significance.

\section{Discussion}

Nocturnal animals on $24 \mathrm{~h}$ light-dark cycles reach peak activity at night, while diurnal animals reach peak activity during the day (Marler \& Hamilton, 1966). In the present study the addition of higher intensity levels of illumination during the opossum's low daytime activity phase led to increased cage activity. Conversely, the addition of these same illumination levels during the high nighttime activity phase led to decreased activity. Thus differences in cage activity produced by ambient illumination are dependent upon the phase of the organ- ism's circadian rhythm cycle at the time of testing. These findings support Bindra's hypothesis (1959) that the relationship between arousal level and performance is best described as an inverted U-shaped curve, with performance increasing to a maximum as a function of increasing arousal level and decreasing beyond this optimal level as a function of further increases in arousal level. In the nocturnal opossum, optimal a rousal would appear to be associated with night and low levels of illumination (see Fig. 1). The addition of higher levels of illumination at this peak nighttime activity phase seems to produce an arousal level high enough to lower cage activity. The addition of low levels of illumination at the low daytime activity phase yields the lowest level of arousal as measured by the least amount of cage activity. Raising the intensity of illumination in the daytime raises the arousal level somewhat and yields an increase in cage activity. This increased activity, however, is still far below that displayed under the optimal arousal conditions of night and dim illumination. These findings have thus demonstrated the necessity for considering the cyclic circadian variations in an organism's arousal level when evaluating the effects of other arousal-producing stimuli.

\section{References}

BINDRA, D. Motivation: A systematic reinterpretation. New York: Ronald Press, 1959.

CAMPBELL, B. A. Effects of water deprivation on random activity. J. comp. physiol. Psychol., 1960, 53, 240-241.

CAMPBELL, B. A., \& SHEFFIELD, F. D. Relation of random activity to food deprivation. J. comp. physiol. Psychol, 1953, 46, 320-322.

CAVAU, A. Drug effects and activation level. In L. M. Uhr and J. G. Miller (Eds.), Drugs and Behavior, New York: John Wiley, 1960. Pp. $409-412$.

DUFFY, E. Activation and behavior. New York: John Wiley, 1962. EDWARDS, A. L. Experimental design in psychological research. (Rev, ed.) New York: Rinehart, 1960.

HALL, V. E., \& LINDSAY, M. The relation of the thyroid gland to the spontaneous activity of the rat. Endocrinology, 1938, 22, 66-79.

ISAAC, W., \& DeVITO, S. L. Effect of sensory stimulation on the activity of normal and prefrontal-lobectomized monkeys. J. comp. physiol. Psychol., 1958, 51, 172-174.

ISAAC, W., \& REED, W. G. The effect of sensory stimulation on the activity of cats. J. comp. physiol. Psychol, 1961, 54, 677-678.

MARLER, P. R., \& HAMILTON III, W. J. Mechanisms of animal behavior. New York: John Wiley, 1966.

RIETVELD, W. J., \& TORDOIR, W. E. M. The influence of light intensity level on locomotor activity of rabbits. Acta Physiologica Et Pharmacologia, 1965, 13, 171-177.

WALKER, H. M., \& LEV, J. Statistical inference. New York: Holt, Rinehart and Winston, 1953. 